\title{
From Primitive Simplicity to Refined Elegance-The Derivation of Modern Thangka Painting Style
}

\author{
Qinghua Hu \\ Qinghai Nationalities University, Xining, China \\ Email: h_qh110@163.com
}

How to cite this paper: Hu, Q. H. (2019). From Primitive Simplicity to Refined Elegance-The Derivation of Modern Thangka Painting Style. Art and Design Review, 7, 145-149.

https://doi.org/10.4236/adr.2019.73013

Received: May 20, 2019

Accepted: August 2, 2019

Published: August 5, 2019

Copyright $\odot 2019$ by author(s) and Scientific Research Publishing Inc. This work is licensed under the Creative Commons Attribution International License (CC BY 4.0).

http://creativecommons.org/licenses/by/4.0/

\section{(c) (i) Open Access}

\begin{abstract}
As a typical national folk art, the painting style of thangka presents traditional brushwork and rich color matching, and forms different schools. Along with the protection and development of thangka, its style also shows the change of living style.
\end{abstract}

\section{Keywords}

Derived Line, Description, Color, School

\section{Introduction}

With the rapid development of cultural industry and tourism as well as the national protection of intangible culture, a large number of folk art obtained the development and innovation. Since the 1980s, thangka is presented from the early pure religious items to the evolution of the nature of the goods such as arts and crafts and collectibles; its inherent artistic style is also undergoing a subtle variation of decoration as the ultimate goal. "Touching and inspiring visitors to buy handicraft itself is the most direct reason for arts and crafts. Reception theory of modern art and aesthetic psychology, also thinks the art acceptance activities are first of all works of art-the most intuitive, external level material medium level, namely, the form of space craft, shape, color, lines, light and shade acceptance" (Li, 2009). The decorative function of thangka, a Tibetan Buddhist art, is fully utilized and expressed. The painting style evolves from the simplicity and gentleness of the old thangka to the elegance and magnificence of the new thangka.

\section{Line Drawing Techniques from Single to Rich}

Line drawing is the essence of the art of thangka painting. Under the deep influ- 
ence of ancient Chinese traditional painting, a single piece of thangka painting is usually completed independently by a way of line drawing, either with gossamer-like line drawing or with willow leaf drawing with changes. The function of line is to summarize the outline and define the main image and its relationship. The current thangka artists, while inheriting, are more deeply aware of the decisive role of line drawing in the achievement of high-level works, and take the spacing and density between lines as the weight elements to reflect the level of painting techniques. Tibetan artists have a very deep line drawing ability, which is consistent with the traditional way of writing and maintains a proper Angle of sight. As thangka painting is a kind of frame painting, they use their own hand-made brush to draw fine, neat and powerful lines from side to side (Kang, 2012), thus the line drawing skill has reached a very high level in Tibetan painting. Therefore, Tibetan painting emphasizes the ability of line drawing, and the excellent line drawing ability is regarded as a magic product. Thus gradually appeared a variety of way to cancel the combination of style, line-drawing form have thick have thin, has permanently changed. The intensive combination of line not only can fully show surface and the transition relationship, also provides the characters of anatomical structure expression possible. Classical delineation is completed by superb line drawing, thangka's masterpiece needs a long time to complete, those big picture, complex composition, many characters, the work of various picture material costs manpower, material resources are also huge. Secondly, the elaboration of line drawing also shows that artists pay more and more attention to the status of secular social life and details of survival. It breaks through the simple worship of faith and pattern-style modeling, and the regional or segmented reality and the visual expression of story plots. It surpasses the purpose of decorative religious patterns and breaks away from the stubborn constraints of measurement, and unconsciously injects painting meaning into the works.

\section{Coloring from Flat to the Gradient, Color Is Given Priority to with Gold}

Early thangka colour to reflect the inherent essence of painting object, full filling method are basically uniform coating, as the thangka style changed, the colors are rich and varied. The harmony of colors and colors is derived from the pure simplicity of primary colors to the elegance and nobility of complex colors details the concept of gradually infiltrated artist color view, knowledge of color gradually rising from perceptual to rational, from the simple to rich color performance, service for decorative and aesthetic features is also growing, the adornment of the thangka colour in the application by local extended to the whole, by summarizing extends to the comprehensive, by a simple depth to the overelaborate. What has unique characteristics is that the relationship between colors in painting is not realized through toning, but artists have unconsciously formed the effect of licking and sucking the brush head in the long-term painting process to achieve the effect of moistening and diluting the saturation of 
pigments. The transition effect is natural and smooth, quietly formed. Although some pigments are toxic, this method of smudging is not available in other paintings. Painting with pure gold is a unique feature of thangka art, a high embodiment of Tibetan aesthetics and values, and a classic in the practical application of color science. Now in addition to the color tang, black tang, there are red tang, gold tang, mainly because the Han region like red, the past gold can't be used, hook gold powder used is not much (Peng, 2012) "in addition to the gold line hook shape, but also gold as the base", now because the collection market is mainly to outsiders, they like hook gold powder hook more than the tang card, appear more brilliant, so now Wutun painter is most often painted black tang, followed by gold paint base color, with agate pen hook line of the gold tang (Peng, 2012) the most ingenious thing is that gold is used to subdivide the difference between platinum and gold and to form the contrast and transition color relationship, so as to make the god world depicted more magnificent.

\section{The School of Painting in the Same Trend of Change}

In the later stage of Tibetan Buddhism, there appeared in succession such masters of painting and sculpture as Dovaja southwest Jia, Yadobu Gongba, Mantang Bamanla Dongzhi, Gongga Dokhin, Garma Quyang Doje and so on. In particular, the "Mantangba" group headed by Mantangba and the "Qinze" group headed by Gonggao Duoqin have produced a kind and beautiful painting technique with "compassionateness" and "furious". Zhuang's serious painting skills are known as the two major painting schools of the world (Gazang, 2001). "The school of thangka painting is closely related to the historical development and regional environment of a certain painting group formed. The long-term practice of Tibetan Buddhism paintings has made this single unchanging and stylized tendency of painting forms also appear in the genre. However, there is no dispute over style between schools, as is often seen in art history. Instead, there is only a style type formed by time and place" (Fei, 1995).

Whether it is the realistic way in which the ancient thangka poured all the skills of the artists into the pure religion, or the decorative effect in which the modern art is the main purpose of creation, they all have a common artistic code, which is the variation of artistic style with decoration as the ultimate goal. Whether specific school or genre depends on the "shoucheng" and "Fazu" in the inheritance, it cannot compare with the most active phenomenon of art, and it will go out of the ancient ways and mud and become more diverse. In the long-term artistic inheritance and competition, artists have surpassed and broken through the ancient programs of the previous thousand Buddhas. Despite the strict measurement scale, there are still differences in the form and spirit of different artists. The characteristics of decoration prompt the current thangka artists to constantly improve their line-drawing skills. The characteristics of detail painting are further strengthened on the basis of traditional styles. Incisively and vividly depicting detail has also become the core content of the artist families and communities in the competition of painting skills. "A large number of 
thangka and thematic decorative paintings try their best to appreciate the unique paintings of miantang, qingzi and gamagong, which do not lose the origin of traditional paintings. Will also have the painting style, painting skills will converge in new drawing picture, on the whole, carry forward the Tibetan art of great achievements" (Kang, 2005). "With the growing of artists team, painting art began to professional scale of road, to form a number of the original painting lineage, painting style, painting communication more frequent, more prompt collection, of diversity in unity of art to a larger, strives for perfection the art of height" (De La, 2009).

Painting style of direction is changed at the same time, the content of the painting also got rich, "before drawing of thangka art is mostly and eulogizing merit good behavior, the value of high and low, mainly to see if a Buddha; its quality is also measured by whether it conforms to traditional measures. However, as a modern art of Tibetan painting, the content of the painting is sometimes Buddha, but not always praise. On the contrary, sometimes also contains the critical content of feudal superstition. As the object of painting, it is not the image of the great virtues of Buddhist monks, but the image of ordinary people to reflect the real life of the people, to praise the power of the people, and sometimes even to reflect the real life of Tibetans by creating some animal images. In addition, there is used a romantic image to reflect the plateau this theme works" (Zong, 2002). On the other hand, the painting team is growing rapidly and new artists keep coming, and thangka's works inevitably resemble god's image of composition, color and technique. As a result, the chaotic phenomena such as forgers and counterfeits in the market transactions prompt some artists with a strong sense of national mission to reflect. A large number of artists also turn their focus from economic value to artistic value, blindly pursuing economic interests and abandoning the original intention of practicing and practicing. Its social effect in the entire inheritance caused much resonance in the crowd.

The value orientation of artworks is not only reflected in the economic benefits. Only with the continuous development and innovation of thangka's artistic individuality can there be real artistic creation. The trend of thangka art should be refinement, not popularization.

\section{Conflicts of Interest}

The author declares no conflicts of interest regarding the publication of this paper.

\section{References}

De La, C. (2009). Tang Ka Painting Course. Fine Arts Publishing House, Shijiazhuang.

Fei, X. (1995). Painting Art of Tibetan Buddhism. China Press Today, Beijing.

Gazang, C. (2001). Unique Tibetan Art. Nationality Publishing House, Lanzhou.

Kang, G. (2005).Tibetan Art History. Sichuan Ethnic Publishing House, Chengdu.

Kang, G. (2012). Tangka Art of Tibetan gamar garze School of Painting. Ethnic Publishing House, Chengdu. 
Li, Y. (2009). Again and Reconstruction: The Contemporary Nature of Traditional Folk Arts and Crafts. Yunnan University Press, Kunming.

Peng, Z. (2012). Regong Tangka Inspection Record. Nationality Publishing House, Lanzhou.

Zong, R. (2002). Introduction to Tibetan Painting Art. Ethnic Publishing House, Qinghai. 